\title{
Implementasi Pengelolaan Data Keuangan Menggunakan MYOB Accounting V18 pada King's Computer
}

\author{
Wati Erawati \\ Universitas Bina Sarana Informatika, Jl. Kramat Raya No. 98, Jakarta, DKI Jakarta, 031065, Indonesia \\ Email: wati.wti@bsi.ac.id
}

\begin{abstract}
The technology deveploment in the current era of globalization has provided many benefits in progress various aspects of human life, especially in the field of technology and communication, as evidenced by the inventions of software or devices that support work in the accounting field. For this reason, this research is about processing accounting data at King's Computer store,which until now has not been effective and efficient in processing data at the store. King's computer store is a store that is engaged in sales, maintenance and computer service services whose financial transaction processes are still carried out manually, namely by recording on paper or in books. Often there is loss of proof of transactions and errors in the recording process, this results in the slow process of making the required financial statements. Manual accounting data processing has more risks than a computerized system. Then this computer system application can be alternative problem solving in processing accounting data at this store. By using the MYOB (Mind Your Own Business) Accounting Plus v18 ED application the user can find out the company's accounting information more accurately and quickly and help the company's operational activities in data processing and providing financial reports so that it runs more effectively and efficiently and can avoid data security problems store financial data. The use of MYOB requires accuracy and discipline from the user, especially when inputting data so that the output produced is as expected. Users are also strongly advised to do a Daily Backup to avoid data loss. In addition, the author also suggests sufficient training for employees so that they will optimize work using the MYOB Accounting Plus V18 software.
\end{abstract}

Keywords: Financial Accounting, Data Processing, MYOB Accounting Plus V18

\begin{abstract}
ABSTRAK
Perkembangan teknologi yang sangat pesat di era globalisasi saat ini telah memberikan banyak manfaat dalam kemajuan diberbagai aspek kehidupan manusia khususnya dibidang teknologi dan komunikasi, terbukti dari adanya penemuan-penemuan software atau perangkat-perangkat yang mendukung pekerjaan dibidang akuntansi. Untuk itu, penelitian ini mengenai pengolahan data akuntansi di Toko King's Komputer yang sampai sekarang pengolahan data di toko tersebut belum efektif dan efesien. Toko King's Komputer adalah toko yang bergerak di bidang penjualan, maintenance dan jasa servis komputer yang proses transaksi keuangannya masih dilakukan secara manual yaitu dengan pencatatan di kertas atau di buku. Seringnya terjadi kehilangan bukti transaksi dan kesalahan dalam proses pencatatan, hal itu mengakibatkan lambatnya proses pembuatan laporan keuangan yang dibutuhkan. Pengolahan data akuntansi secara manual memiliki lebih banyak resiko dibandingkan dengan sistem yang sudah terkomputerisasi. Maka aplikasi sistem komputer ini dapat menjadi alternatif pemecahan masalah dalam pengolahan data akuntansi pada toko ini. Dengan menggunakan aplikasi MYOB (Mind Your Own Business) Accounting Plus v18 ED user dapat mengetahui informasi akuntansi perusahaan lebih akurat dan cepat dan membantu kegiatan operasional perusahaan dalam pengolahan data dan penyediaan laporan keuangan sehingga berjalan lebih efektif dan efisien serta dapat terhindar dari masalah keamanan data-data keuangan toko. Penggunaan MYOB membutuhkan ketelitian dan kedisiplinan dari pengguna, terutama pada saat penginputan data agar output yang dihasilkan sesuai dengan yang diharapkan. Pengguna juga sangat disarankan melakukan Daily Backup untuk menghindari terjadinya kehilangan data. Selain itu penulis juga menyarankan pelatihan yang cukup kepada karyawan sehingga akan lebih mengoptimalkan kerja dengan penggunaan software MYOB Accounting Plus V18.
\end{abstract}

Kata Kunci: Pengolahan Data, Akuntansi Keuangan, MYOB Accounting Plus v18 


\section{Pendahuluan}

Perkembangan teknologi informasi cukup besar berpengaruh dalam dunia bisnis terlebih di masa pandemi saat ini. Salah satunya yaitu komputer, hal ini dikarenakan komputer adalah suatu alat yang sangat dibutuhkan oleh perusahaan yang mampu membuat, mengolah serta menyimpan data yang sangat efektif, akurat dan efisien. Teknologi informasi diartikan sebagai ilmu pengetahuan dalam bidang informasi yang berbasis komputer dan perkembangannya sangat pesat[1]. Revolusi Industri 4.0, yang menandai adanya era ekonomi digital dengan otomatisasi mekanis dalam menjalani laju perekonomian. Istilah lain untuk revolusi industri adalah revolusi digital dan era korupsi teknologi. Revolusi digital ini merupakan proses proliferasi komputer dan otomatisasi proses perekaman di berbagai bidang. Fase keempat dari revolusi teknologi ini mengubah cara manusia bergerak dan berinteraksi dalam skala, ruang lingkup, kompleksitas, dan transformasi dari pengalaman hidup sebelumnya sehingga manusia dapat merasakan kehidupan dalam ketidakpastian global[2].

Perusahaan dalam menjalankan usahanya pasti membutuhkan pencatatan keuangan. Dalam hal ini masih terdapat beberapa perusahaan yang pencatatan keuangan nya masih belum efektif. Seperti halnya pencatatan keuangan di King's komputer ini pencatatannya masih menggunakan sistem yang belum efektif dan akurat untuk hasil laporannya dan juga memakan waktu yang cukup lama dalam pembuatan laporan. Laporan keuangan menurut [3] adalah laporan pertanggungjawaban pimpinan perusahaan atas pengelolaan perusahaan yang dipercayakan kepadanya kepada pihak-pihak luar perusahaan. Sistem Informasi Akuntansi digunakan untuk mengumpulkan, memproses, dan melaporkan informasi yang berkaitan dengan aspek keuangan dari peristiwa bisnis. Sistem Informasi Akuntansi mencatat dan melaporkan transaksi bisnis dan aliran dana dalam organisasi dan kemudian menghasilkan Laporan Keuangan[4].

Seperti penelitian sebelumnya menurut [5] menggunakan MYOB dalam laporan keuangan terbukti bahwa proses laporan keuangan dapat lebih cepat dan akurat, dikarenakan tampil secara otomatis laporan-laporan yang dibutuhkan dari proses yang dilakukan oleh sistem, keberhasilan suatu perusahaan dalam mencapai suatu tujuan yang telah disepakati bersama tidak terlepas dari sistem-sistem yang menyediakan informasi-informasi yang akurat dan terpercaya, aplikasi akuntansi seperti MYOB memiliki ketelitian yang tinggi. Dari hal ini dapat disimpulkan aplikasi MYOB dapat mempermudah dan mempercepat pengolahan data dan menampilkan laporan keuangan lebih cepat.

Menurut [6] MYOB Accounting adalah sebuah paket software olah data akuntansi yang yang dibuat secara terpadu dan dapat digunakan hanya satu user saja. Menurut [7] Akuntansi adalah proses dari transaksi yang dibuktikan dengan faktur, lalu dari transaksi dibuat jurnal, buku besar, neraca lajur, kemudian akan menghasilkan informasi dalam bentuk laporan keuangan yang digunakan pihak-pihak tertentu. Menurut [8] Akuntansi sebagai kumpulan konsep dan teknik yang digunakan untuk mengukur dan melaporkan informasi keuangan dalam suatu unit usaha ekonomi. Dari kedua definisi diatas dapat disimpulkan akuntansi adalah kegiatan mengolah data akuntansi yang digunakan untuk mengukur dan menginformasikan dalam bentuk laporan keuangan yang mencerminkan keadaan perusahaan kepada pihak-pihak yang berkepentingan.

Menurut [9] Siklus akuntansi adalah laporan keuangan berupa laporan operasional, laporan perubahan ekuitas dan nerasa serta laporan realisasi anggaran seperti yang dihasilkan melalui proses akuntansi. Siklus akuntansi digambarkan di bawah ini: 


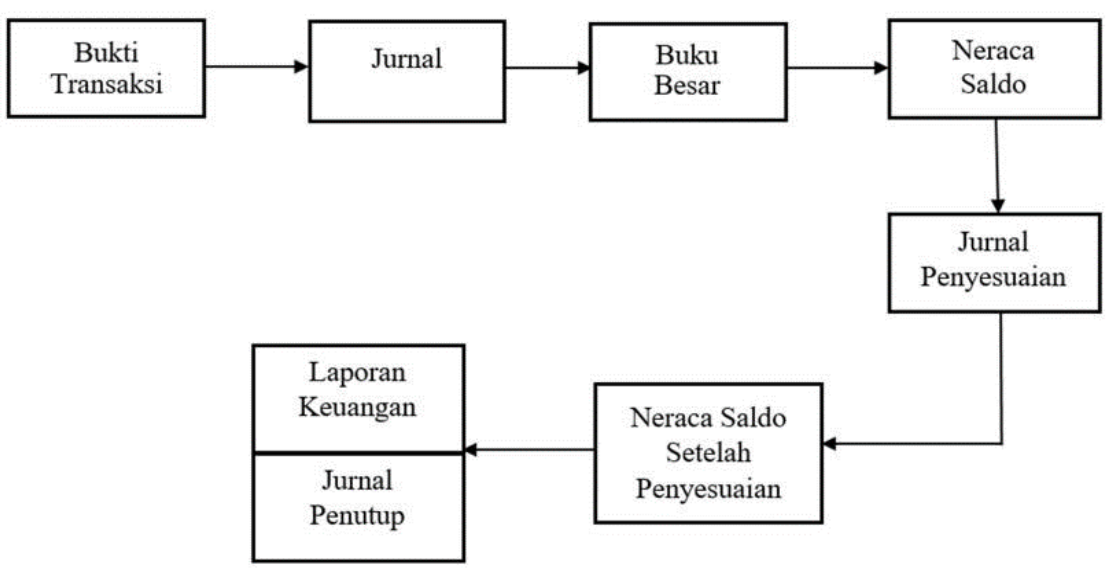

Gambar 1. Siklus Akuntansi [9]

Menurut [10] Sistem informasi akuntansi diartikan sebagai suatu komponen yang mengumpulkan, menggolongkan, mengolah, menganalisis dan mengkombinasikan informasi keuangan yang relevan untuk pengambilan keputusan. Menurut [11] Sistem Informasi Akuntansi menyatakan bahwa Sistem informasi akuntansi lebih mengarah pada data dibandingkan informasi, meskipun menghasilkan sebagian informasi, SIA menyajikan basis data bagi sistem informasi lain.

Menurut [12] Laporan keuangan pada dasarnya adalah hasil dari proses akuntansi yang dapat digunakan sebagai alat untuk mengkomunikasikan data keuangan atau aktivitas perusahaan kepada pihak-pihak yang berkepentingan.

Tools aplikasi yang digunakan pada penelitian ini adalah MYOB Accounting Plus v18 ED. MYOB adalah salah satu software akuntansi yang cukup popular di kalangan para accounting dan pengusaha di Indonesia, software akuntansi ini sangat umum digunakan untuk mencatat seluruh transaksi bisnis dan menghasilkan laporan keuangan secara otomatis. Aplikasi MYOB ini adalah berbagai jenis perusahaan jasa, dagang, manufaktur dan keuangan, tidak hanya perusahaan besar saja yang dapat menggunakan aplikasi MYOB ini, perusahaan - perusahaan menengah dan kecil pun dapat ikut mengguanakan aplikasi ini.

Menurut [13] Penggunaan MYOB mengikuti pedoman yang berlaku pada windows seperti $\mathrm{CTRL}+\mathrm{C}$ untuk menggandakan dan CTRL+V untuk menyalin dan sebagainya. Bukan hal yang sulit jika sudah terbiasa menggunakan MYOB dengan program-program yang beroperasi di dalam platform windows.

\section{Metode}

Metode yang digunakan dalam penelitian ini adalah metode kualitatif deskriptif yaitu metode penelitian memanfaatkan data kualitatif dan dijabarkan secara deskriptif dan lebih menekankan pada aspek pemahaman secara mendalam terhadap suatu masalah serta dilakukan studi kepustakaan yaitu menggunakan berbagai referensi dari beberapa buku dan artikel online. Selain metode tersebut beberapa tahapan metode penelitian yang digunakan yaitu diawali dengan perencanaan, pengumpulan data, pengolahan data dan penerapan data ke aplikasi MYOB Accounting V18. Adapun tahapan-tahanpan itu di antaranya:

1. Perencanaan

Dalam tahap ini penulis penulis membuat susunan penelitian terhadap masalah - masalah yang ditemui selama penelitian. Tahapan awal yaitu perencanaan sangat dibuthkan untuk menunjang pencapaian tujuan penelitian ke tahap- tahap berikutnya.

2. Pengumpulan Data 
Pada tahapan ini, penulis membutuhkan pengamatan serta observasi secara langsung pada perusahaan untuk mengetahui permasalahan yang ada, seperti kebutuhan hardware, kebutuhan software dan kebutuhan staff yang utama sebagai operator nantinya dari usulan hasil penelitian.

3. Pengolahan Data

Dalam tahapan ini yaitu penulis melanjutkan dari tahapan pengumpulan data, setelah itu data yang terkumpul diidentifikasi pada tahapan ini yang sangat berguna nantinya untuk melanjutkan ke tahapan akhir.

4. Penerapan Data ke Aplikasi Myob Accounting V18

Tahapan ini merupakan tahapan akhir dari metoide penelitian yang penulis gunakan. Di tahapan ini akan dimulai dengan cara instalasi software yang digunakan pada komputer, dalam hal ini yaitu MYOB Accounting V18. Untuk lebih jelasnya di abwa ini akan digambarkan dalam bentuk bagan tahapan penerapan data ke aplikasi Myob Accounting V18.

\section{Hasil dan Pembahasan}

King's Komputer adalah toko yang bergerak dalam bidang komputer yang mencakup penjualan, maintenance dan service. Sistem pencatatan keuangan pada Toko King's Komputer masih belum menggunakan software akuntansi. Umumnya usaha kecil menengah (UKM) belum banyak yang melakukan pencatatan keuangan secara terorganisir, karena banyak kendala seperti sumber daya manusia yang belum memenuhi maupun karena keterbatasan alat penunjangnya.

Sistem pencatatan akuntansi manual dibuat untuk memenuhi kebutuhan perusahaan dalam membuat laporan keuangan. Dalam pencatatan akuntansi manual, semua transaksi yang bersumber dari nota dan sebagainya dicatat dijurnal umum, kemudian dipindahkan ke buku besar, selanjutnya merancang neraca saldo, laba rugi, perubahan modal dan neraca hingga diaplikasikan ke dalam aplikasi MYOB Accounting Plus V18 ED. Berikut penulis akan menguraikan transaksi yang terjadi pada Toko King's Komputer.

\section{Gambaran Sistem Usulan}

Sistem usulan disusun bertujuan untuk memperbaiki sistem berjalan yang telah diterapkan di perusahaan agar mempercepat proses pencatatan terutama dari sisi pelaporan keuangan manfaat dari aplikasi Myob Accounting V18 ini juga sudah banyak digunakan di perusahan menengah.

\section{Prosedur Yang Diusulkan}

Dalam hal ini penulis mengusulkan Flow of System dalam bentuk flowchart terkait pelaporan keuangan yang digambarkan di bawah ini: 
@is The Best: Accounting Information Systems and Information Technology Business Enterprise

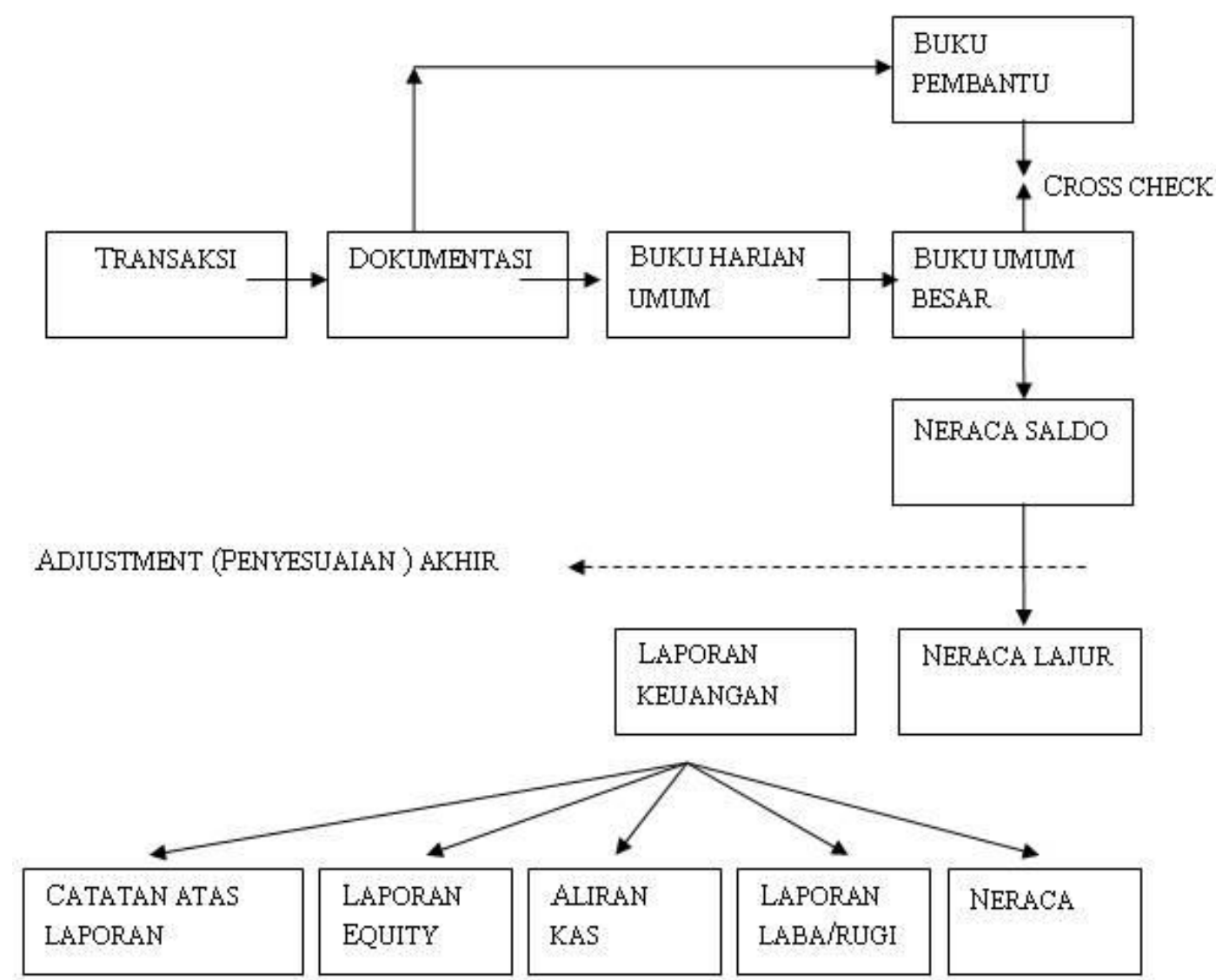

Gambar 2. Flow of System Pelaporan Keuangan

Dari hasil penelitian di King's Komputer berikut adalah neraca saldo per 31 Desember 2019 pencatatan secara manual.

Tabel 1. Saldo Awal Akun

\begin{tabular}{|c|c|c|c|}
\hline \multicolumn{4}{|c|}{$\begin{array}{c}\text { King's Computer } \\
\text { Neraca Saldo } \\
\text { Periode } 31 \text { Desember } 2019 \\
\end{array}$} \\
\hline \multirow{2}{*}{$\begin{array}{l}\text { Kode } \\
\text { Akun }\end{array}$} & \multirow{2}{*}{ Nama Akun } & \multicolumn{2}{|c|}{ Saldo Awal } \\
\hline & & Debet & Kredit \\
\hline $1-1100$ & Kas & $\begin{array}{ll}\text { Rp. } & 5.800 .000\end{array}$ & \\
\hline $1-1300$ & Bank Mandiri & Rp. 10.400 .000 & \\
\hline $1-1400$ & Piutang Dagang & $\begin{array}{ll}\text { Rp. } & 4.527 .500 \\
\end{array}$ & \\
\hline $1-1500$ & Persediaan Barang Dagang & Rp. 40.289 .788 & \\
\hline $1-2100$ & Peralatan & Rp. 10.304 .000 & \\
\hline $1-2110$ & Akumulasi Peny. Peralatan & & Rp. 2.500 .000 \\
\hline $1-1600$ & Perlengkapan Toko & $\begin{array}{ll}\text { Rp. } & 2.000 .000 \\
\end{array}$ & \\
\hline $2-1000$ & Hutang Dagang & & Rp. 22.303.788 \\
\hline $3-1100$ & Modal Usaha & & Rp. 50.943 .500 \\
\hline & Total & Rp. 75.747.288 & Rp. 75.747 .288 \\
\hline
\end{tabular}

Sumber: Toko King’s Computer

Tabel di atas merupakan pencatatan neraca saldo dari hasil pencatatan secara manual pada periode 31 Desember 2019. Dari perhitungan neraca saldo tersebut menunjukan nominal Rp75.747.288,00,--

Berikut Data Persediaan barang dagang per 31 Desember 2019: 
@ is The Best: Accounting Information Systems and Information Technology Business Enterprise ISSN: 2252-9853 (Print) | ISSN: 2656-808X (Online)

Tabel 2. Saldo Awal Persediaan Barang Dagang

\begin{tabular}{|c|c|c|c|c|c|c|}
\hline No. & ID & Nama Barang & Unit & Harga Jual & HPP & Jumlah \\
\hline 1 & B01 & $\begin{array}{l}\text { Notebook Acer } \\
\text { Aspire ES1-132-C44T }\end{array}$ & 1 & Rp3.700.000 & Rp2.700.000 & Rp2.700.000 \\
\hline 2 & B02 & $\begin{array}{l}\text { Notebook ASUS } \\
\text { X200MA-KX674B }\end{array}$ & 1 & Rp3.205.900 & Rp2.205.900 & Rp2.205.900 \\
\hline 3 & B03 & $\begin{array}{l}\text { Notebook Dell } \\
\text { Inspiron 11-3162 }\end{array}$ & 1 & Rp3.500.000 & Rp2.500.000 & Rp2.500.000 \\
\hline 4 & B04 & $\begin{array}{l}\text { Laptop ASUS } \\
\text { E402WA-GA001T }\end{array}$ & 1 & Rp4.100.000 & Rp3.100.000 & Rp3.100.000 \\
\hline 5 & B05 & $\begin{array}{l}\text { Laptop HP 14- } \\
\text { bw005AU }\end{array}$ & 1 & Rp4.250.000 & Rp3.250.000 & Rp3.250.000 \\
\hline 6 & B06 & $\begin{array}{l}\text { LCD LED Laptop } \\
14 \text { ” X200 }\end{array}$ & 1 & Rp565.000 & Rp250.000 & Rp250.000 \\
\hline 7 & B07 & $\begin{array}{l}\text { LCD LED Laptop } \\
\text { 14" Slim 30pin }\end{array}$ & 1 & Rp735.000 & Rp420.000 & Rp420.000 \\
\hline 8 & B08 & Baterai Dell PD945 & 1 & Rp427.590 & Rp112.590 & Rp112.590 \\
\hline 9 & B09 & $\begin{array}{l}\text { Baterai Acer Aspire } \\
\text { V5-431 }\end{array}$ & 1 & Rp445.000 & Rp130.000 & Rp130.000 \\
\hline 10 & $\mathrm{~B} 10$ & $\begin{array}{l}\text { Baterai Lenovo } \\
\text { Original BL242 }\end{array}$ & 1 & Rp440.000 & Rp125.000 & Rp125.000 \\
\hline 11 & B11 & $\begin{array}{l}\text { Hardisk Eksternal } \\
\text { Toshiba Canvio Basic } \\
\text { 3.0 }\end{array}$ & 2 & Rp975.000 & Rp660.000 & Rp1.320.000 \\
\hline 12 & B12 & $\begin{array}{l}\text { Hardisk Eksternal } \\
\text { Adata HD710 2TB }\end{array}$ & 2 & Rp1.555.000 & Rp1.240.000 & Rp2.480.000 \\
\hline 13 & B13 & $\begin{array}{l}\text { Logitech Mouse B100 } \\
\text { Wired USB }\end{array}$ & 6 & Rp225.000 & Rp70.000 & Rp420.000 \\
\hline 14 & B14 & $\begin{array}{l}\text { Logitech Wireless M } \\
\text { M170 }\end{array}$ & 5 & Rp270.750 & Rp115.750 & Rp578.750 \\
\hline 15 & B15 & $\begin{array}{l}\text { Logitech Desktop } \\
\text { MK120 }\end{array}$ & 5 & $\mathrm{Rp} 275.500$ & Rp120.500 & Rp602.500 \\
\hline 16 & B16 & $\begin{array}{l}\text { Flashdisk Sanddisk } \\
\text { Cruzer Fit 32GB }\end{array}$ & 8 & Rp223.700 & Rp68.700 & Rp549.600 \\
\hline 17 & B17 & $\begin{array}{l}\text { Flashdisk Sanddisk } \\
\text { Ultra Dual Drive USB } \\
\text { Type-C 16GB }\end{array}$ & 8 & Rp505.000 & Rp350.000 & Rp2.800.000 \\
\hline 18 & B18 & $\begin{array}{lr}\text { Speaker } & \text { Bluetooth } \\
\text { Mini } & \text { Wireless } \\
\text { Portable } & \\
\end{array}$ & 7 & Rp210.000 & Rp55.000 & Rp385.000 \\
\hline 19 & B19 & $\begin{array}{lll}\text { Tinta } & \text { Canon } & 41 \\
\text { Colour } & & \\
\end{array}$ & 5 & Rp565.000 & Rp250.000 & Rp1.250.000 \\
\hline 20 & $\mathrm{~B} 20$ & Tinta Canon 40 Black & 5 & Rp535.000 & Rp220.000 & Rp1.100.000 \\
\hline 21 & B21 & $\begin{array}{l}\text { Processor Intel Core } \\
\text { I3-8100 }\end{array}$ & 3 & Rp2.327.448 & Rp2.012.448 & Rp6.037.344 \\
\hline 22 & B22 & $\begin{array}{l}\text { Processor Intel Core } \\
\text { I5-4460 }\end{array}$ & 3 & Rp2.490.000 & Rp2.175.000 & Rp6.525.000 \\
\hline
\end{tabular}


@is The Best: Accounting Information Systems and Information Technology Business Enterprise ISSN: 2252-9853 (Print) | ISSN: 2656-808X (Online)

\begin{tabular}{|c|c|c|c|c|c|c|}
\hline No. & ID & Nama Barang & Unit & Harga Jual & HPP & Jumlah \\
\hline 23 & B23 & $\begin{array}{ll}\text { Motherboard } & \text { Asus } \\
\text { H110M-E LGA } & 1151\end{array}$ & 1 & Rp1.538.104 & Rp1.223.104 & Rp1.233.104 \\
\hline 24 & B24 & $\begin{array}{l}\text { Votre KM-310 } \\
\text { Optical Mouse }\end{array}$ & 5 & Rp170.000 & Rp15.000 & Rp75.000 \\
\hline 25 & B25 & $\begin{array}{ll}\text { Votre } & \text { KB-2308 } \\
\text { Keyboard } & \\
\end{array}$ & 5 & Rp185.000 & Rp30.000 & Rp150.000 \\
\hline & & Total & 80 & Rp33.418.992 & Rp23.398.992 & Rp40.289.788 \\
\hline
\end{tabular}

Sumber : Toko King's Computer

Tabel di atas merupakan pencatatan saldo awal persediaan barang dari hasil pencatatan secara manual pada periode 31 Desember 2019. Dari perhitungan saldo awal persediaan barang di dapat total Rp40.289.788.

Di bawah ini adalah data-data transaksi selama bulan Januari 2020:

Tabel 3. Data-Data Transaksi

\begin{tabular}{|c|c|c|}
\hline \multicolumn{2}{|c|}{ Tanggal } & Keterangan \\
\hline $\begin{array}{c}\text { Januari } \\
2020\end{array}$ & 1 & $\begin{array}{l}\text { Penjualan tunai kepada Pak Tama dengan no bukti SJ-01 sebesar Rp. } 2.442 .825 \\
\text { (Termasuk PPN) } \\
\text { - Hardisk Ekternal Toshiba Canvio Basic } 3.0 \text { 2pc @ Rp.975.000=Rp. } \\
\text { 1.950.000 } \\
\text { - Logitech Wireless Mouse M170 } \\
270.750\end{array}$ \\
\hline & 2 & $\begin{array}{l}\text { Menerima pendapatan jasa memperbaiki IC Power laptop dari jam } 09.30-14.46 \\
\text { yang langsung ditagih tunai oleh karyawan Cakra dengan no bukti CRJ-01 } \\
\text { sebesar Rp. } 665.500 \text { (Termasuk PPN) }\end{array}$ \\
\hline & 3 & $\begin{array}{l}\text { Pembelian tunai kepada Global Telcomindo no bukti PJ-01 sebesar Rp. } \\
\text { 1.452.000 (Termasuk PPN) dengan biaya angkut pembelian Rp. } 100.000 \text {, berupa: } \\
\text { - Hardisk Ekternal Toshiba Canvio Basic } 3.0 \text { 2pcs @ Rp. } 660.000=\text { Rp. } \\
\text { 1.320.000 }\end{array}$ \\
\hline & 4 & $\begin{array}{l}\text { Penjualan tunai kepada Dela dengan no bukti SJ-02 sebesar Rp. } 1.243 .000 \\
\text { (Termasuk PPN) } \\
\text { - Tinta Canon } 41 \text { Colour 2pc @ Rp. } 565.000=\text { Rp. } 1.130 .000\end{array}$ \\
\hline & 4 & Membayar listrik, air dan telp dengan no bukti CDJ-01 sebesar Rp. 1.000 .000 \\
\hline & 5 & $\begin{array}{l}\text { Penjualan barang dagang kepada MHM Computer secara kredit termin 2/10 } \\
\text { n/30 no bukti SJ-03 sebesar Rp. 7.070.192,8 (Termasuk PPN) dengan uang } \\
\text { muka sebesar Rp. } 1.000 .000 \\
\begin{array}{l}\text { - Laptop ASUS E402WA-GA001T1pc @ Rp. } 4.100 .000=\text { Rp. } 4.100 .000 \\
\text { - Processor Intel Core I3-8100 1pc @ RP. 2.327.448= Rp. } 2.327 .448\end{array}\end{array}$ \\
\hline & 6 & 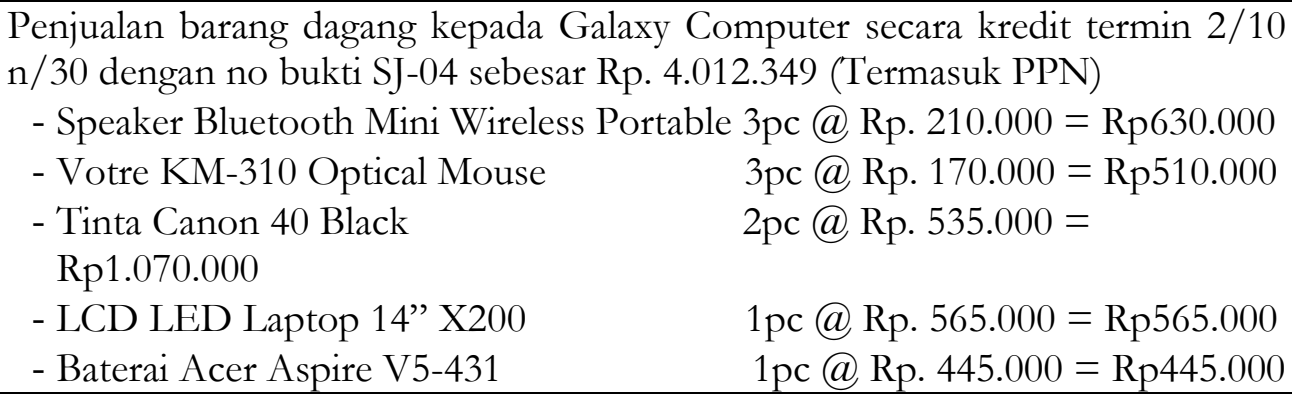 \\
\hline
\end{tabular}


@is The Best: Accounting Information Systems and Information Technology Business Enterprise ISSN: 2252-9853 (Print) | ISSN: 2656-808X (Online)

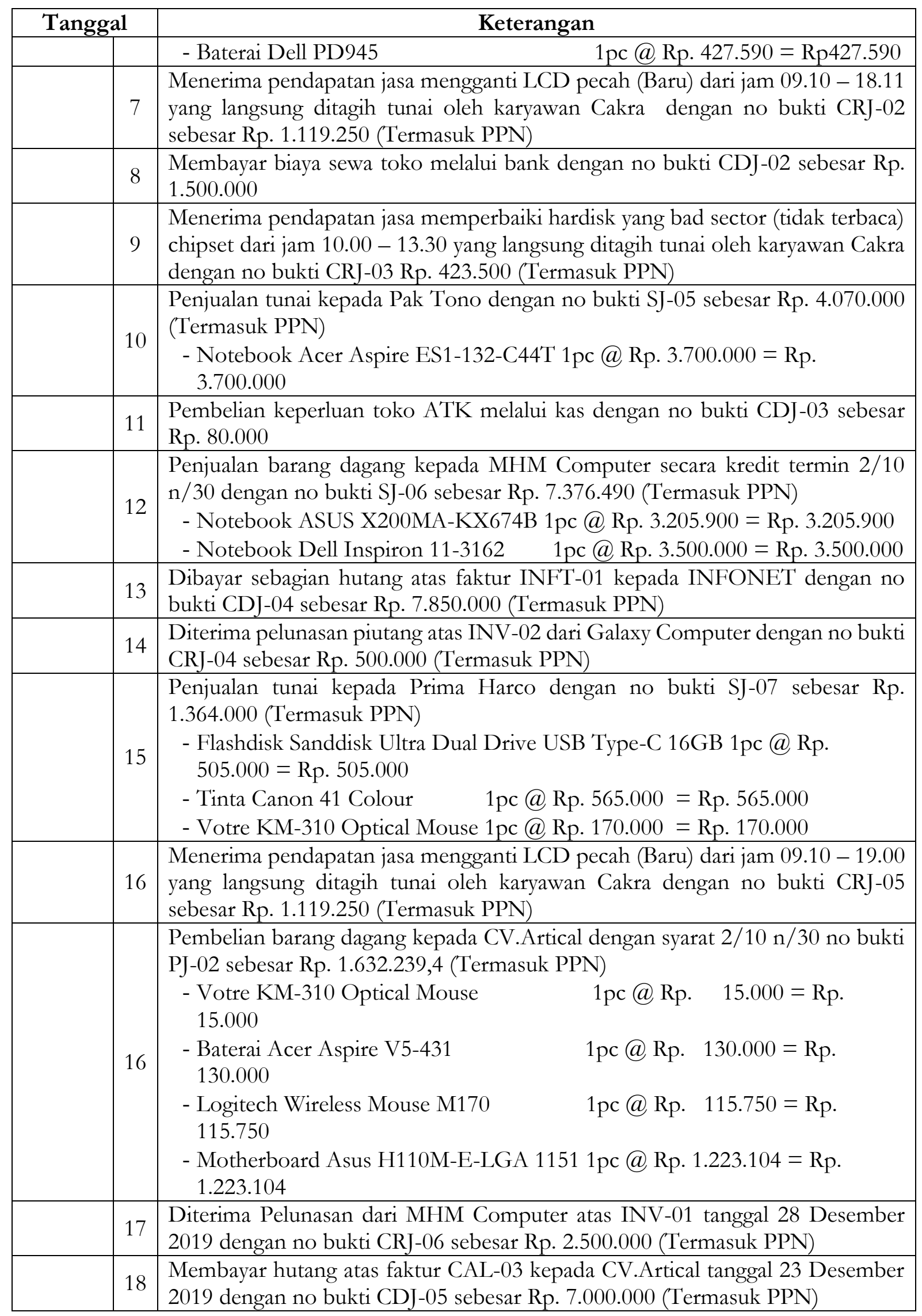


@is The Best: Accounting Information Systems and Information Technology Business Enterprise ISSN: 2252-9853 (Print) | ISSN: 2656-808X (Online)

\begin{tabular}{|c|c|}
\hline Tanggal & Keterangan \\
\hline 18 & $\begin{array}{l}\text { Penjualan tunai kepada Rafli dengan no bukti SJ-08 sebesar Rp. } 297.825 \\
\text { (Termasuk PPN) } \\
\text { - Logitech Wireless Mouse M170 1pc @ Rp. } 270.750=\text { Rp. } 270.750\end{array}$ \\
\hline 19 & $\begin{array}{l}\text { Pembelian tunai kepada Global Telcomindo dengan no bukti PJ-03 sebesar Rp. } \\
275.000 \text { (Termasuk PPN) } \\
\text { - Tinta Canon } 41 \text { Colour 1pc @ Rp. } 250.000=\text { Rp. } 250.000\end{array}$ \\
\hline 20 & $\begin{array}{l}\text { Menerima pembayaran piutang dari MHM Computer atas faktur SJ-06 dengan } \\
\text { no bukti CRJ-07 sebesar Rp. } 7.228 .960,2 \text { mendapat potongan Rp. 147.529,8 } \\
\text { melalui bank mandiri }\end{array}$ \\
\hline 20 & $\begin{array}{l}\text { Menerima pendapatan jasa mengganti LCD rusak (Second) dari jam } 12.40- \\
18.00 \text { yang langsung ditagih tunai oleh karyawan Cakra dengan no bukti CRJ-08 } \\
\text { sebesar Rp. } 665.500 \text { (Termasuk PPN) }\end{array}$ \\
\hline 21 & $\begin{array}{l}\text { Pengembalian barang ke CV.Artical atas faktur PJ-02 karena cacat dengan no } \\
\text { bukti PRJ-01 sebesar Rp. } 16.500 \text { (Termasuk PPN) } \\
\text { - Votre KM-310 Optical Mouse 1pc @ Rp. } 15.000=\text { Rp. } 15.000\end{array}$ \\
\hline 21 & $\begin{array}{l}\text { Menerima pendapatan jasa menginstall ulang laptop (termasuk semua app siap } \\
\text { pakai) dari jam } 11.25-12.41 \text { yang langsung ditagih tunai oleh karyawan Cakra } \\
\text { dengan no bukti CRJ-09 sebesar Rp. } 181.500 \text { (Termasuk PPN) }\end{array}$ \\
\hline 22 & $\begin{array}{l}\text { Penjualan barang dagang secara kredit kepada Galaxy Computer dengan no } \\
\text { bukti SJ-09 sebesar Rp. } 4.695 .570 \text { (Termasuk PPN) } \\
\text { - Processor Intel Core I5-4460 } 1 \text { 1pc @ Rp. 2.490.000=Rp. } 2.490 .000 \\
\text { - Flashdisk Sanddisk Cruzer Fit 32GB 1pc @ Rp. } 223.700=\text { Rp. } \\
\text { - Hardisk Ekternal Adata HD710 2TB 1pc @ Rp. 1.555.000= Rp. } 1.555 .000\end{array}$ \\
\hline 23 & $\begin{array}{l}\text { Menerima pendapatan jasa mengganti LCD pecah (Baru) dari jam } 09.25-18.30 \\
\text { yang langsung ditagih tunai oleh karyawan Cakra dengan no bukti CRJ-10 } \\
\text { sebesar Rp. } 1.119 .250 \text { (Termasuk PPN) }\end{array}$ \\
\hline 24 & $\begin{array}{l}\text { Menerima pendapatan jasa memperbaiki motherboard mati total (blank screen) } \\
\text { dari jam } 10.00 \text { - } 12.00 \text { yang langsung ditagih tunai oleh karyawan Cakra dengan } \\
\text { no bukti CRJ-11 sebesar Rp. } 242.000 \text { (Termasuk PPN) }\end{array}$ \\
\hline 25 & 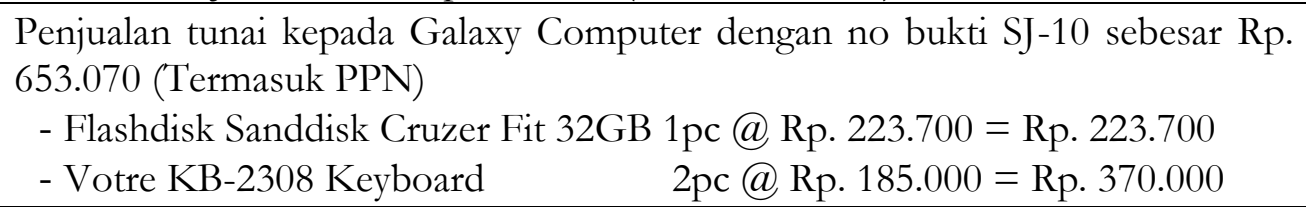 \\
\hline 26 & $\begin{array}{l}\text { Diterima pelunasan piutang atas faktur SJ-03 dari MHM Computer tanggal } 05 \\
\text { Januari } 2020 \text { dengan no bukti CRJ-12 sebesar Rp. 6.000.000 (Termasuk PPN) }\end{array}$ \\
\hline 26 & $\begin{array}{l}\text { Membayar gaji karyawan secara tunai bulan Desember } 2019 \text { dengan no bukti } \\
\text { CDJ-06 sebesar Rp. } 10.050 .000 \text { melalui kas }\end{array}$ \\
\hline 26 & $\begin{array}{l}\text { Membayar hutang kepada Cv.Artical atas faktur PJ-02 tanggal } 16 \text { Januari } 2020 \\
\text { dengan no bukti CDJ-07 sebesar Rp. } 1.500 .000 \text { (Termasuk PPN) }\end{array}$ \\
\hline 27 & $\begin{array}{l}\text { Membayar hutang atas faktur GTO-02 kepada Global Telcomindo tanggal } 18 \\
\text { Desember } 2019 \text { dengan no bukti CDJ-08 sebesar Rp. } 5.000 .000 \text { (Termasuk } \\
\text { PPN) }\end{array}$ \\
\hline 27 & $\begin{array}{l}\text { Menerima pendapatan jasa memperbaiki IC Power laptop dari jam } 11.25-17.56 \\
\text { yang langsung ditagih tunai oleh karyawan Cakra dengan no bukti CRJ-13 } \\
\text { sebesar Rp. } 816.750 \text { (Termasuk PPN) }\end{array}$ \\
\hline
\end{tabular}


@is The Best: Accounting Information Systems and Information Technology Business Enterprise ISSN: 2252-9853 (Print) | ISSN: 2656-808X (Online)

\begin{tabular}{|c|c|}
\hline Tanggal & Keterangan \\
\hline 28 & $\begin{array}{l}\text { Diterima barang dari Galaxy Computer atas faktur SJ-04 karena cacat dengan no } \\
\text { bukti SRJ-01 sebesar Rp. } 231.000 \text { (Termasuk PPN) } \\
\text { - Speaker Bluetooth Mini Wireless Portable 1pc @ Rp. } 210.000=\text { Rp. } \\
210.000\end{array}$ \\
\hline 29 & $\begin{array}{l}\text { Penjualan barang dagang secara kredit MHM Computer dengan no bukti SJ-11 } \\
\text { sebesar Rp. 5.692.500 (Termasuk PPN) } \\
\text { - Flashdisk Sanddisk Ultra Dual Drive USB Type-C 16GB 1pc @ Rp. } \\
\quad 505.000=\text { Rp. } 505.000 \\
\text { - Speaker Bluetooth Mini Wireless Portable 2pc @ Rp. } 210.000=\text { Rp. } \\
\quad \text { 420.000 } \\
\text { - Laptop HP 14-bw005AU } \\
\begin{array}{l}\text { 4.250.000 } \\
\text { 1pc @ Rp. } 4.250 .000=\text { Rp. }\end{array}\end{array}$ \\
\hline 30 & $\begin{array}{l}\text { Diterima pelunasan piutang dari Galaxy Computer atas faktur SJ-04 tanggal } 6 \\
\text { Januari } 2020 \text { dengan no bukti CRJ-14 sebesar Rp. } 3.700 .000 \text { (Termasuk PPN) }\end{array}$ \\
\hline 31 & $\begin{array}{l}\text { Pemakaian perlengkapan periode ini sebesar Rp. } 75.000 \text { dengan no bukti AJP- } \\
01\end{array}$ \\
\hline 31 & $\begin{array}{l}\text { Peralatan disusutkan dengan menggunakan metode garis lurus dan diketahui } \\
\text { harga perolehan peralatan Rp. } 3.500 .000 \text {, taksiran umur ekonomis } 5 \text { tahun dan } \\
\text { taksiran nilai residu Rp. } 780.000 \text { sebesar Rp. } 544.000 \text { dengan no bukti AJP-02 }\end{array}$ \\
\hline 31 & Biaya sewa untuk periode ini sebesar Rp. 1.500 .000 dengan no bukti AJP-03 \\
\hline
\end{tabular}

Sumber: Toko King's Computer

Tabel di atas merupakan pencatatan transaksi-transaksi dari hasil analisa dokumen selama bulan Januari 2020. Dimana pencatatan tersebut mulai tanggal 1 hingga 31 Desember 2020. Implementasi Program.

1. Tampilan Awal MYOB

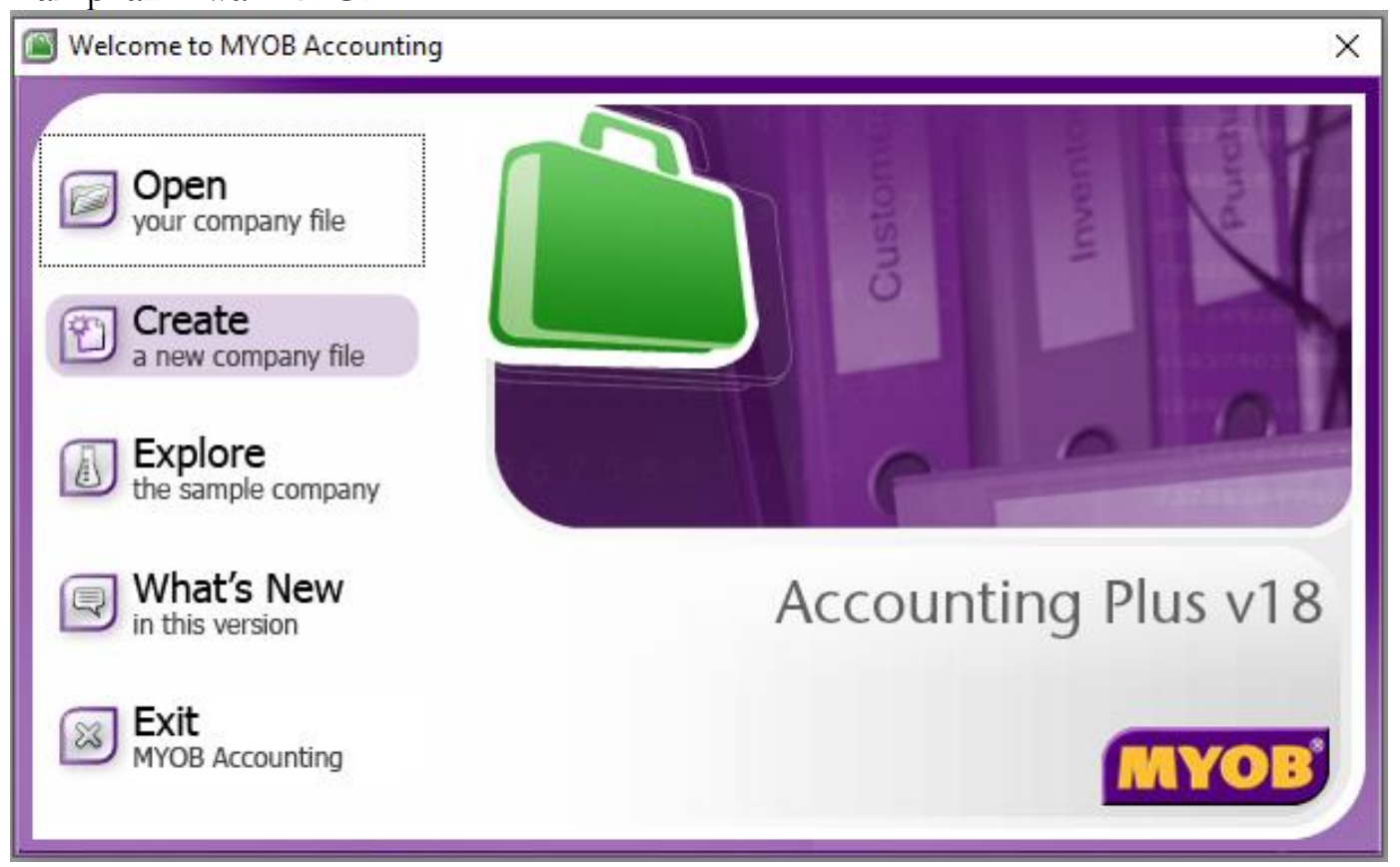

Gambar 3. Tampilan menu utama MYOB Accounitng Plus V.18 
@is The Best: Accounting Information Systems and Information Technology Business Enterprise ISSN: 2252-9853 (Print) | ISSN: 2656-808X (Online)

Gambar diatas merupakan tampilan awal dari software ABSS pada saat user membuka aplikasi ABSS. Untuk memulai pembuatan pengolahan database perusahaan baru maka klik menu Create. Untuk membuka database yang telah kita buat maka pilih menu Open.

2. Tampilan Company Information

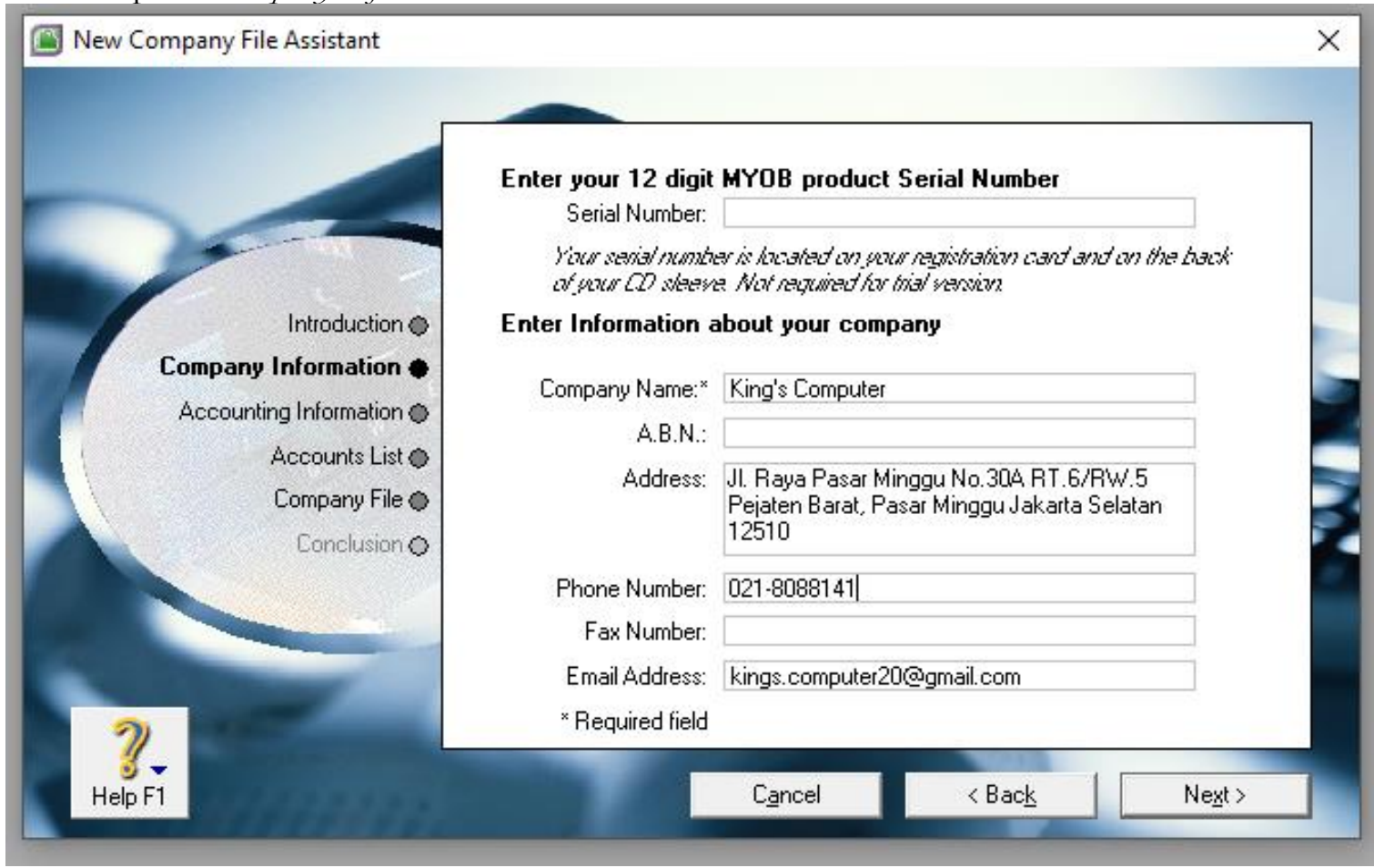

Gambar 4. Tampilan Company Infromation

Gambar di atas menunjukan menu Company Information yaitu untuk penginputan database perusahaan.

3. Tampilan Command Centre/Modul-Modul Di MYOB

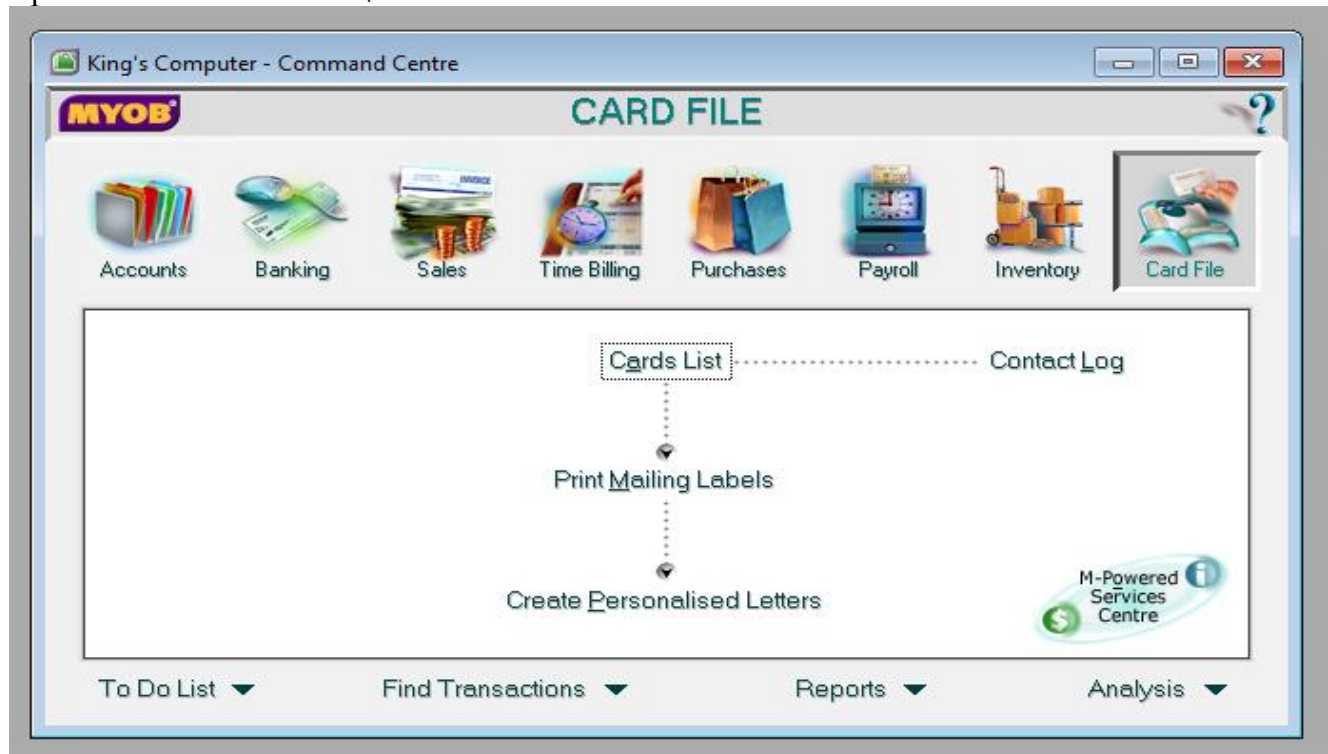

Gambar 5. Tampilan Command Centre

Volume 6 Nomor 2 (2021) Hal. 106-120 
@is The Best: Accounting Information Systems and Information Technology Business Enterprise

ISSN: 2252-9853 (Print) | ISSN: 2656-808X (Online)

Gambaran di atas menunjukan menu utama di aplikasi ABSS setelah menyelesaikan penginputan database perusahaan.

4. Tampilan Neraca Saldo/Account Opening Balance

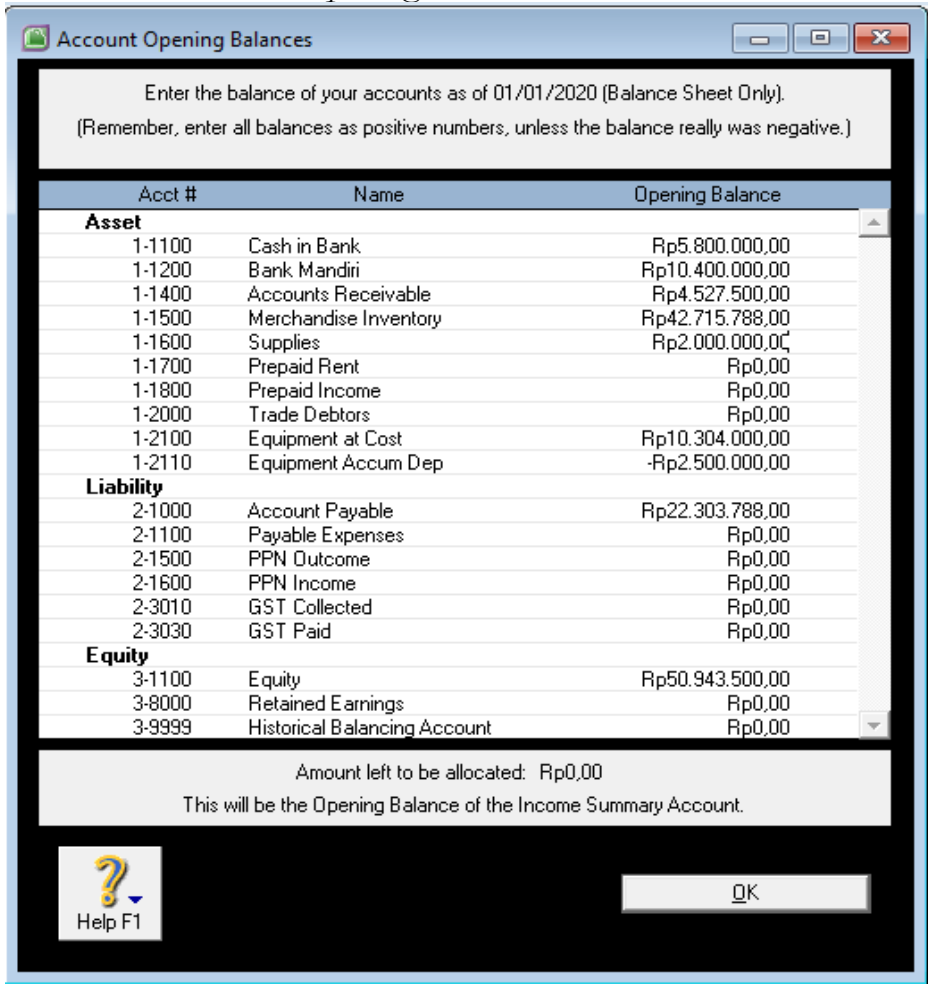

Gambar 6. Tampilan Account Opening Balance di input.

Gambaran di atas menunjukan tampilan menu Account Opening Balance dari data yang sudah

5. Tampilan Penginputan Transaksi Penjulan Tunai

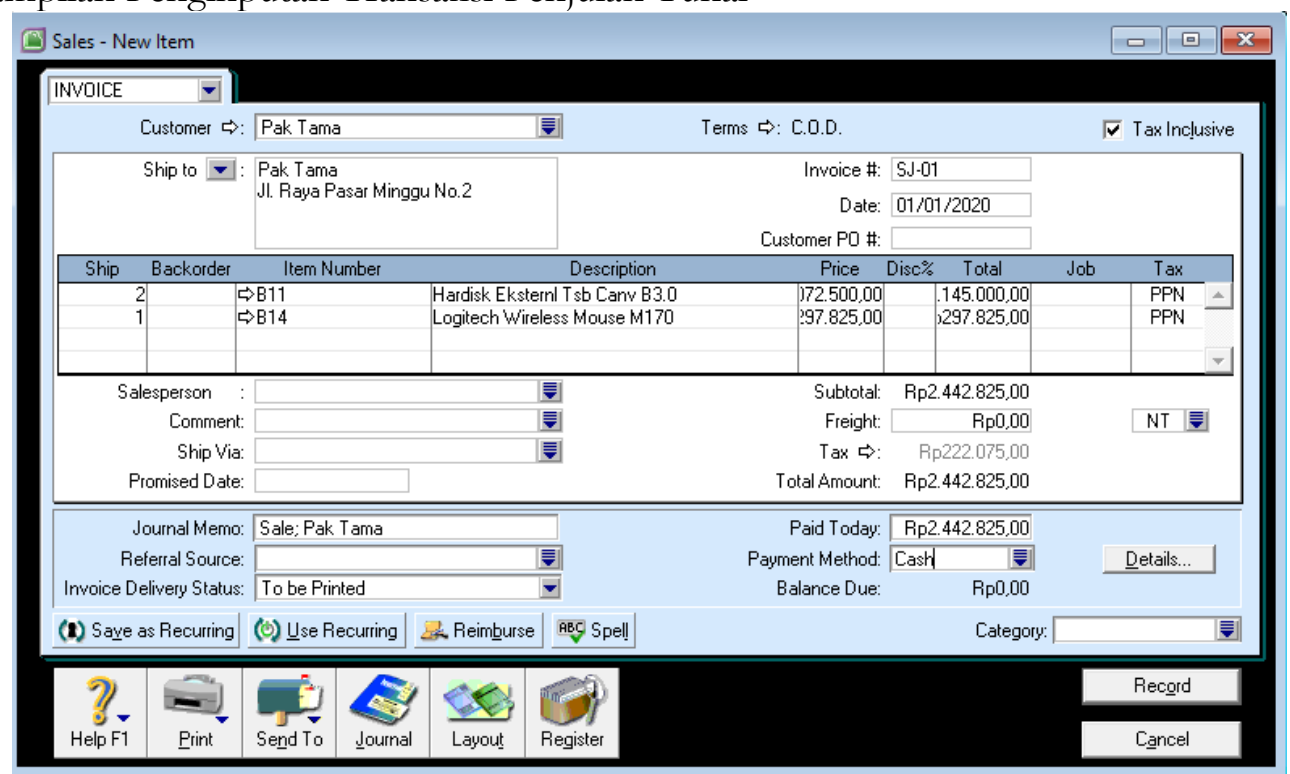

Gambar 7. Transaksi Penjualan Tunai

Volume 6 Nomor 2 (2021) Hal. 106-120 
@is The Best: Accounting Information Systems and Information Technology Business Enterprise

ISSN: 2252-9853 (Print) | ISSN: 2656-808X (Online)

Gambaran di atas menunjukan tampilan menu untuk penginputan transaksi penjualan tunai.

6. Tampilan Penginputan Transaksi Pembelian Tunai

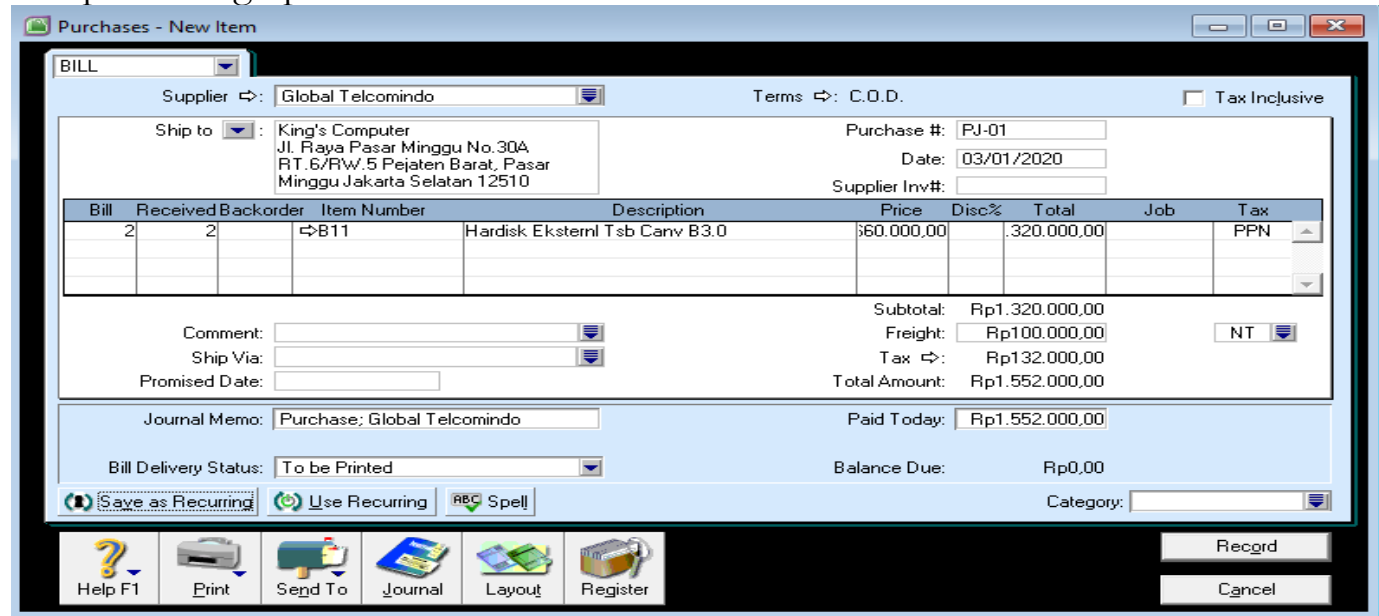

Gambar 8. Transaksi Pembelian Tunai

Gambaran di atas menunjukan tampilan menu untuk penginputan transaksi pembelian tunai.

7. Tampilan Laporan Laba/Rugi

\begin{tabular}{|c|c|}
\hline \multicolumn{2}{|c|}{$\begin{array}{l}\text { King's Computer } \\
\text { J. Raya Pasar Minggu No.30A RT.6/RW.5 Pejaten Barat, Pasar Minggu Jakarta Sel } \\
\text { Profit \& Loss Statement } \\
\text { January } 2020\end{array}$} \\
\hline $\begin{array}{l}\text { Income } \\
\text { Service Income } \\
\text { Sales } \\
\text { Sales Return } \\
\text { Sales Discounts } \\
\text { Total Income }\end{array}$ & $\begin{array}{l}\text { Rp5.775.000,00 } \\
\text { Rp35.379.838,00 } \\
-\operatorname{Rp} 210.000,00 \\
-\operatorname{Rp} 134.118,00 \\
\quad \operatorname{Rp} 40.810 .720,00 \\
\end{array}$ \\
\hline $\begin{array}{l}\text { Cost Of Sales } \\
\text { Cost of Goods Sold } \\
\text { Freight Out } \\
\text { Total Cost Of Sales }\end{array}$ & $\begin{array}{l}\text { Rp23.594.838,00 } \\
\text { Rp100.000,00 } \\
\text { Rp23.694.838,00 }\end{array}$ \\
\hline Gross Profit & Rp17.115.882,00 \\
\hline $\begin{array}{l}\text { Expenses } \\
\text { Telephon\&Electricity Expenses } \\
\text { Supplies Expenses } \\
\text { Rent Expenses } \\
\text { Wages \& Salaries } \\
\text { Depreciation Expenses } \\
\text { Total Expenses }\end{array}$ & $\begin{array}{l}\text { Rp1.000.000,00 } \\
\text { Rp75.000,00 } \\
\text { Rp3.000.000,00 } \\
\text { Rp10.050.000,00 } \\
\text { Rp544.000,00 } \\
\quad \text { Rp14.669.000,00 }\end{array}$ \\
\hline Operating Profit & Rp2.446.882,00 \\
\hline $\begin{array}{l}\text { Other Income } \\
\text { Other Expenses }\end{array}$ & \\
\hline Net Profit(Loss) & Rp2.446.882,00 \\
\hline
\end{tabular}

Gambar 9. Tampilan Laporan laba/rugi

Gambaran ini atas merupakan hasil penginputan data berupa laporan laba/rugi perusahaan. 
@is The Best: Accounting Information Systems and Information Technology Business Enterprise ISSN: 2252-9853 (Print) | ISSN: 2656-808X (Online)

8. Tampilan Neraca Saldo

\begin{tabular}{|c|c|c|c|c|}
\hline \multirow{2}{*}{\multicolumn{5}{|c|}{$\begin{array}{l}\text { King's Computer } \\
\text { JI. Raya Pasar Minggu No.30A RT.6/RW.5 Pejaten Barat, Pas } \\
\text { Trial Balance } \\
\text { January } 2020\end{array}$}} \\
\hline & & & & \\
\hline 2020 & Debit & Credit & YTD Debit & YTD Credit \\
\hline $\begin{array}{l}\text { Cash in Bank } \\
\text { Bank Mandiri } \\
\text { Accounts Receivable } \\
\text { Merchandise Inventory } \\
\text { Supplies } \\
\text { Prepaid Rent } \\
\text { Equipment at Cost } \\
\text { Equipment Accum Dep } \\
\text { Account Payable } \\
\text { Payable Expenses } \\
\text { PPN Outcome } \\
\text { PPN Income } \\
\text { Equity } \\
\text { Service Income } \\
\text { Sales } \\
\text { Sales Return } \\
\text { Sales Discounts } \\
\text { Cost of Goods Sold } \\
\text { Freight Out } \\
\text { Telephon\&Electricity Expenses } \\
\text { Supplies Expenses } \\
\text { Rent Expenses } \\
\text { Wages \& Salaries } \\
\text { Depreciation Expenses }\end{array}$ & $\begin{array}{r}\text { Rp5.728.960,20 } \\
\text { Rp8.539.611,80 } \\
\text { Rp5.000,00 } \\
\text { Rp0,00 } \\
\text { p19.734.260,60 } \\
\text { Rp303.885,40 }\end{array}$ & $\begin{array}{r}\text { Rp1.697.594,00 } \\
\text { p20.555.984,00 } \\
\text { Rp1.500.000,00 } \\
\text { Rp544.000,00 } \\
\text { Rp3.486.186,00 } \\
\text { Rp4.081.072,00 } \\
\text { Rp0,00 } \\
\text { Rp5.775.000,00 } \\
\text { p35.379.838,00 }\end{array}$ & $\begin{array}{r}\text { Rp210.000,00 } \\
\text { Rp134.118,00 } \\
\text { p23.594.838,00 } \\
\text { Rp100.000,00 } \\
\text { Rp1.000.000,00 } \\
\text { Rp75.000,00 } \\
\text { Rp3.000.000,00 } \\
\text { p10.050.000,00 } \\
\text { Rp544.000,00 }\end{array}$ & $\begin{array}{l}\text { Rp1.500.000,00 } \\
\text { Rp3.044.000,00 } \\
\text { Rp2.569.527,40 } \\
\text { Rp3.486.186,00 } \\
\text { Rp4.081.072,00 } \\
\\
\text { p50.943.500,00 } \\
\text { Rp5 } .775 .000,00 \\
\text { p35.379.838,00 }\end{array}$ \\
\hline Total: & p73.019.674,00 & p73.019.674,00 & $106.779 .123,40$ & $106.779 .123,40$ \\
\hline
\end{tabular}

\section{Kesimpulan}

Gambar 10. Tampilan Neraca Saldo

Penggunaan software MYOB Accounting Plus V18 dapat membantu proses pekerjaan laporan keuangan sehingga lebih akurat, efektif dan efisien. Perusahaan juga dapat lebih mudah dalam pengambilan keputusan karena pada proses pencatatan akuntansi sudah sesuai standar akuntansi yang berlaku. Penggunaan aplikasi mampu menghasilkan laporan keuangan dengan cepat karena setelah data di input dalam jurnal maupun laporan dapat langsung ditampilkan. Sedangkan pembuatan laporan secara manual memerlukan buku besar, neraca saldo dan neraca lajur dalam membuat laporan sehingga memakan waktu cukup lama. Laporan neraca yang dihasilkan oleh MYOB tidak terpisah dari laporan perubahan modal. Oleh karena itu dapat memudahkan pembaca laporan atau pemangku kepentingan untuk menganalisa laporan tersebut. Namun penggunaan MYOB membutuhkan ketelitian dan kedisiplinan dari pengguna, terutama pada saat penginputan data agar output yang dihasilkan sesuai dengan yang diharapkan. Pengguna juga sangat disarankan melakukan Daily Backup untuk menghindari terjadinya kehilangan data. Selain itu penulis juga menyarankan pelatihan yang cukup kepada karyawan sehingga akan lebih mengoptimalkan kerja dengan penggunaan software MYOB Accounting Plus V18.

\section{Ucapan Terima kasih}

Peneliti mengucapkan terima kasih kepada semua pihak yang telah mendukung dan membantu dalam memberikan data maupun informasi untuk tujuan penilitian ini. Ucapan terima 
kasih juga kepada pihak editor atau reviewer yang telah memberikan kesempatan saya sebagai penulis untuk menerbitkan penelitian saya ini.

\section{Daftar Pustaka}

[1] R. Prasojo,Lantip Diat, Teknologi Informasi Pendidikan. Yogyakarta: Gava Media, 2011.

[2] Supriyati, R. S. Bahri, and E. Komarudin, "Computerized of International Financial Report Standard for Good Governance in Small Medium Enterpreses," in IOP Conference Series: Materials Science and Engineering, 2019, vol. 662, no. 5, doi: 10.1088/1757899X/662/5/052009.

[3] Bambang Wahyudiono, Mudah Membaca Laporan Kenangan. Jakarta: Raih Asa Sukses, 2014.

[4] S. Mulyani, E. Kasim, W. Yadiati, and H. Umar, "Influence of accounting information systems and internal audit on fraudulent financial reporting," Opcion, vol. 35, no. 21, pp. 323-338, 2019.

[5] A. Wahyuningsih, "Implementasi Akuntansi Sistem Pembelian dan Penjualan Obat Dengan Menggunakan Aplikasi MYOB Accounting Pada Praktek Kedokteran," J. Sisfokom (Sistem Inf. dan Komputer), vol. 2, no. 2, pp. 5-11, 2013, doi: 10.32736/sisfokom.v2i2.89.

[6] Tim Litbang Wahana Komputer, Langsung Praktik Komputerisasi Akuntansi Dengan Myob. Semarang: Wahana Komputer, 2015.

[7] Sujarweni, Pengantar Akuntansi. Yogyakarta: Pustaka Baru Press, 2016.

[8] M. . Hutauruk, Akuntansi Perusahaan Jasa Aplikasi Program Zabir Accounting Versi 6. Jakarta: Indeks, 2017.

[9] M. dan Sumini, Siklus Akuntansi Satuan Kerja Perangkat Daerah SKPD. Mitra Wacana Media, 2017.

[10] S. C. Utami, D. S. P. Astuti, and M. R. Sunarko, "Pengaruh Kemampuan Pengguna Sistem Informasi, Keterlibatan Pengguna, Dan Dukungan Manajemen Puncak Terhadap Kinerja Sistem Informasi Akuntansi pada PT BTPN Area Surakarta," J. Akunt. dan Sist. Teknol. Inf., vol. 12, no. 2, pp. 208-220, 2016.

[11] Normah, "Komunikasi Data Bisnis Dan Keuangan Berbasis CBIS Menggunakan Zahir Accounting," Indones. J. Comput. Inf. Technol., vol. 2, no. 1, pp. 38-45, 2017.

[12] Hery, Akuntansi Sektor Jasa Dan Dagang. Jakarta: PT. Grasindo, 2016.

[13] Haryani, "Implementasi ERP Dalam Pengolahan Data Elektronika Kas Guna Menunjang Efektifitas Pengendalian Internal Penerimaan Kas," Perspektif, vol. XIII, p. 32, 2015. 